\title{
Tongue Squamous Cell Carcinoma and Ill Fitting Dental Prostheses
}

Nouha Dammak ${ }^{1,2^{*}}$, Sameh Sioud ${ }^{1,2}$, Maroua Garma ${ }^{1,2}$, Mounir Omami1 ${ }^{1,2}$, Adel Bouguezzi ${ }^{1,2}$, Abdellatif Chokri ${ }^{1,2}$, Mohamed Habib Hamdi ${ }^{1,2}$, Jamil Selmi ${ }^{1,2}$

${ }^{1}$ Oral Medicine, Oral Surgery Department, University Clinic of Dental Medicine, Monastir, Tunisia

${ }^{2}$ Oral Health and Oro-Facial Rehabilitation Laborotary (LR12ES11), Faculty of Dental Medicine, University of Monastir, Tunisia

DOI: $10.36347 /$ sjmcr.2020.v08i10.015

| Received: 22.09.2020 | Accepted: 02.10.2020 | Published: 29.10.2020

*Corresponding author: Nouha Dammak

Abstract

Case Report

Introduction: Squamous cell carcinoma (SCC) of the tongue has a relatively high incidence of all oral cancers. Some studies have reported a relationship between dental prostheses and tongue SCC. The aim of this work was to warn dentist against the fatal consequences of inappropriate dental prostheses. Observation: A 64-year-old female patient consulted with the chief complain of a tongue ulceration. This lesion has been related to an ill fitting mandibular dental prosthesis. Clinical and histological finding confirmed the diagnosis of SCC. Conclusion: Chronic trauma presents a risk factor for oral cancers, so a big attention must be given to teeth or dental protheses in the treatment of premalignant lesions or cancers of the oral cavity.

Keywords: Carcinoma, Squamous Cell/ Oral Ulcer/ dental protheses.

Copyright $(\mathcal{C} 2020$ The Author(s): This is an open-access article distributed under the terms of the Creative Commons Attribution 4.0 International License (CC BY-NC 4.0) which permits unrestricted use, distribution, and reproduction in any medium for non-commercial use provided the original author and source are credited.

\section{INTRODUCTION}

Oral squamous cell carcinoma (OSCC) is a malignant epithelial tumor that primarily affects men between sixth and seventh decades of life and is commonly located in the tongue comprising 25 to $40 \%$ of oral cancers [1].

The cause of OSCC is multifactorial. The classical etiologic ones are alcohol consumption and chronic tobacco. Nutritional deficiency, immunosuppression [2], oncogenic human papilloma viruses [3] have been also established as etiologic factors for these tumors. In addition, chronic oral mucosa irritation has been prouved as a risk factor, and the main cause of this trauma is ill fitting dental prostheses [4].

We report a case of a SCC of the tongue which seems to be the result of an ill fitting dental prostheses chronic trauma.

\section{Case Report}

A 64-year-old female patient, with an uneventful medical history, consulted the Oral Medicine, Oral Surgery Department at the University Clinic of Dental Medicine, with a chief complain of an ulcerated lesion of the tongue. It was associated with mild pain.
The patient was a non-smoker and did not consume alcohol. The extraoral examination was without relevant specifities and concluded the absence of lymphadenopathy on palpation.

Intraoral examination revealed an ulceration on the right border of the tongue with induration on palpation (Figure-1).

She stated that she has been using a mandibular dental prosthesis for 6 years ago (Figure-2). She revealed that this lesion had been evolving for two years and enlarged progressively.

The lesion was initially described by the patient as a prothesis trauma but incisional biopsyproven well differentiated SCC on histopathologic evaluation (Figure-3).

The IRM showed thad lesion measured $3 \mathrm{~cm}$ (Figure-4). The tumor was classified T2N0M0 according to the TNM system. The patient was referred to the maxillofacial surgery department for best management.

The tumor was surgically removed and no adjuvant therapies were needed (Figure-5). The histologicol finding of the excised lesion confirmed the diagnosis of SCC. No signs of recurrence have been observed after two years of follow-up. 


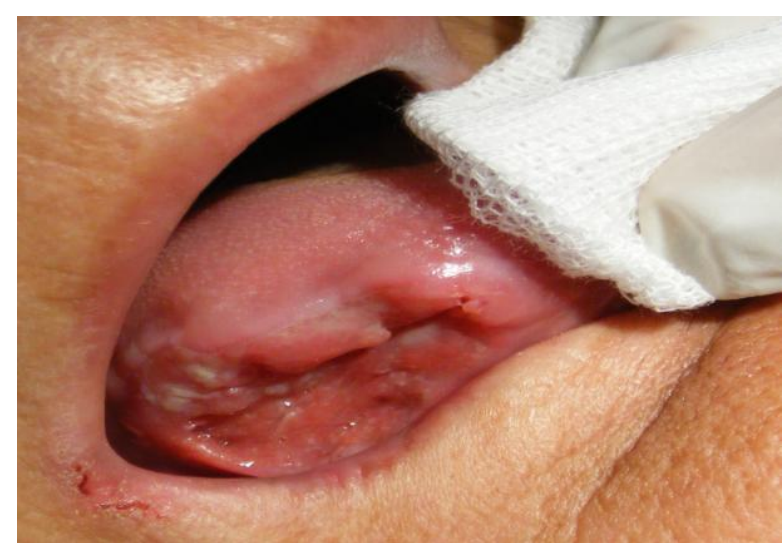

Fig-1: Ulcerated lesion on the right border of the tongue

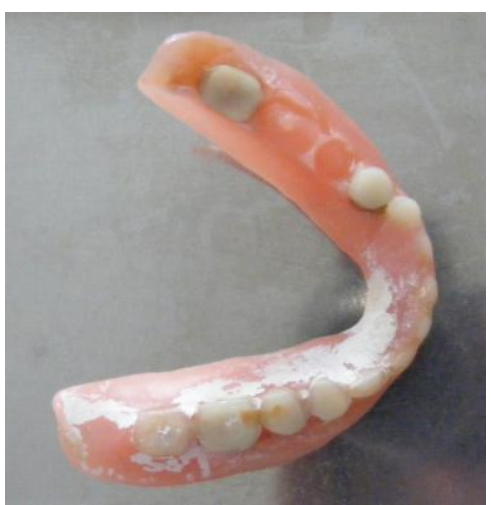

Fig-2: Dental prothesis

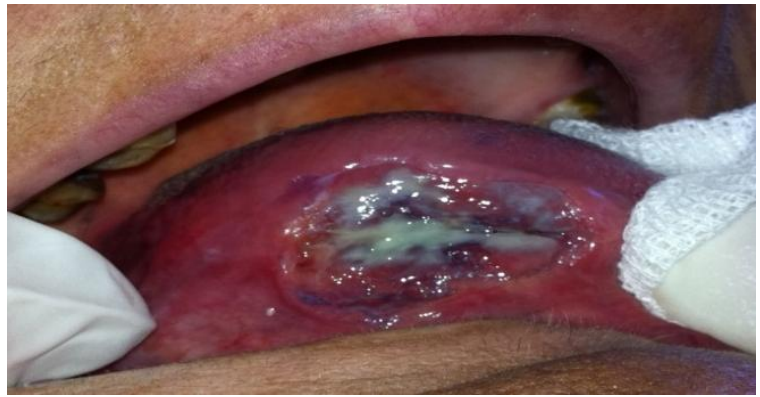

Fig-3: Lesion aspect after biopsy

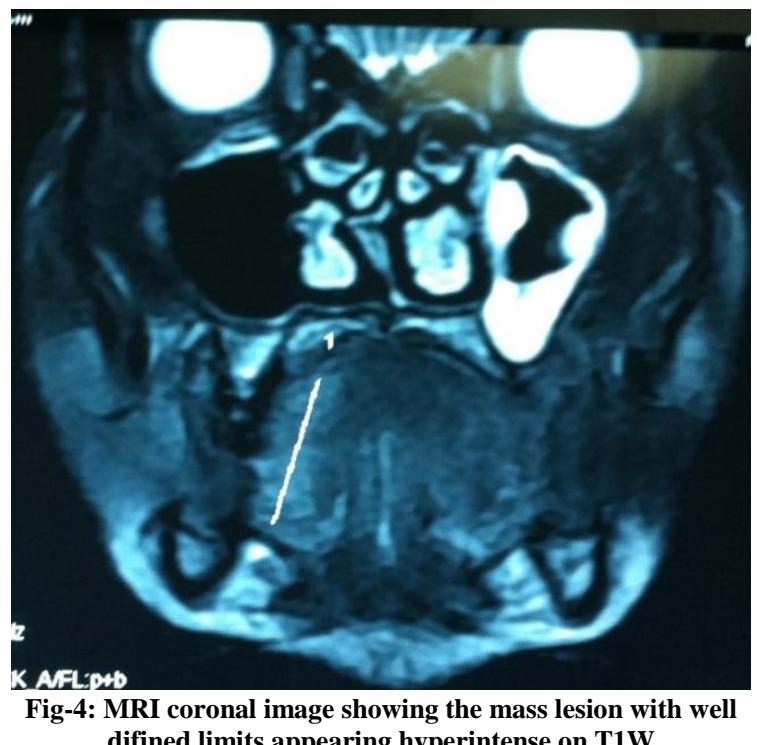

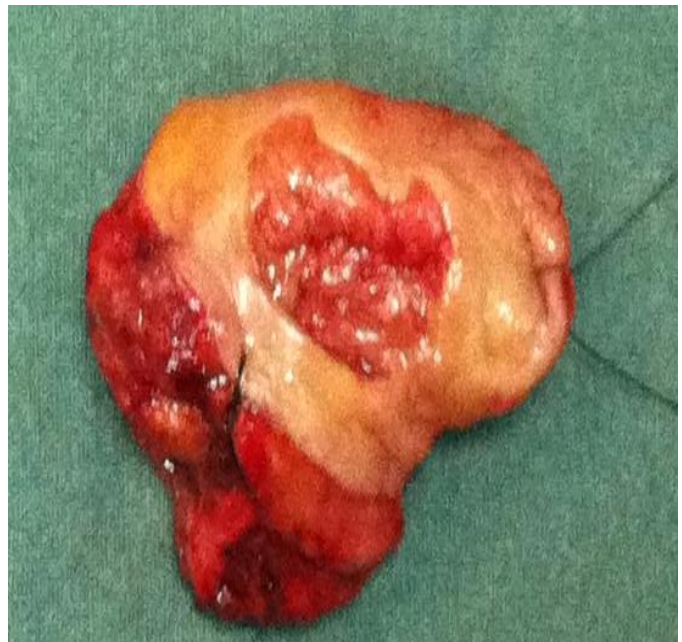

Fig-5: Surgical resection of the lesion

\section{DiscuSSION}

Head and neck cancer presents 3 to $5 \%$ of all cancer, being the sixtieth cancer worldwide $[5,6]$. The most common, more than $90 \%$, and the most malignant type of oral tumors is SCC [7, 8].

For our patient, tumor lesion was located on the posterior right border and slightly extended on the ventral surface of the tongue. That was in agreement with literature, as the most common oral localization is the tongue [3], and usually the posterior lateral border and ventral surfaces are the most frequent site of involvement [9].

It is usually observed in males between 40-50 years of age [8]. Several risk factors of OSCC have been identified, and it is believed to be a multifactorial condition [8].

Tobacco and alcohol are often considered as the major risk factors for this cancer. However, they could not cause the entirety of cancers, and also there are patients unexposed to those factors that could develop such malignant lesions [10].

Furthermore, it has been proposed that chronic oral mucosa irritation, such as the presense of ill fitting dental protheses, may potentially contribute to the development or agravate oral cancers.

A literature review [4] showed that chronic mucosa irritation resulting from ill-fitting dental protheses may be considered as a risk factor for the cancer development.

A meta-analysis [11] concluded that the use of dental protheses by itself is associated with an increased risk of cancer development. In addition, ill-fitting dental protheses seems to seriously increase by almost four times the risk of cancer development. 
If chronic trauma is a carcinogen, it would be expected that a high incidence of OSCC would occur near fractured teeth, sharp restauration and ill fitting dental protheses, especially on the lateral border of the tongue or the buccal mucosa [2]. A literature review [4] concluded that such cancers occur commonly over the lateral border of the tongue. This result may be explained by the mobility of the tongue while chewing and talking increasing the possibility of sores.

Fan $\mathrm{H}$ et al., [8] found that patients with bridges and/or crowns exhibited higher frequency of SCC on the tongue compared to patients without these prostheses.

From available literature, there was no correlation between the lifetime use of dental protheses and cancer development $[4,11]$.

The same meta analysis [11] showed also that among nonaddicts cancers which are associated to dental protheses are seen more frequently in females, as in our case.

The SCC of our patient was the consequence to chronic trauma related to an ill fitting mandibular dental prothesis. This finding was in agreement with literature as most of cancers related to dental protheses were attributed to the use of ill-fitting mandibular ones [12].

Indeed, the anatomical characteristics of the mandible may explain the poor retention of a dental prosthesis [12].

Several studies have been assessed the role of chronic trauma in carcinogenesis. Experimental animal studies have suggested that chronic trauma can lead to cancer by two mechanisms. First, it has been proposed that chronic irritation causes DNA damage and may eventually result in cancer development. This has been proven by increased activity of poly-ADP-ribose polymerase in cases with chronic trauma. According to second proposed mechanism, chronic trauma results in inflammation, thereby releasing chemical mediators such as cytokine, prostaglandins, and tumor necrosis factor, which leads to oxidative stress. This could induce genetic and epigenetic changes damaging DNA, inhibiting its repair, altering transcription factors, preventing apoptosis, and stimulating angiogenesis, thus resulting in carcinogenesis $[4,11]$.

Velly AM et al., [13], in a retrospective study on upper aerodigestive tract cancer patients, found a lower mean nodal staging in patients with cancers adjacent to teeth and dental prostheses. Lockhart PB et al., [14] found that patients with partial or full dental protheses -associated cancers had significantly lower node scores than patients without dental prostheses.
Magnetic resonance imaging (MRI) is routinely used to evaluate head and neck cancers and provide a wealth of information regarding depth of invasion, tissue and lymphadenopathy extent, osseous erosion, perineural spread, and other factors [15]. For our case MRI was demanded to explore the exact size and extension of the lesion.

The treatment of OSCC is generally multidisciplinary [6]. Complete surgical resection is the gold standard treatment in most cases and can be associated with other oncological treatment with good functional outcomes especialy for early stage cancers, as in this case.

\section{CONCLUSION}

The adequate oral rehabilitation, appropriate monitoring of dental prostheses and regular follow up represent a non-negligible scope for cancer prevention. Patient has to consult when any oral lesion appear, as earlier detection of malignancies is the gold standard of improving the prognosis and the quality of life of patients.

Conflicts of Interest: The authors declare that there is no conflict of interests.

\section{REFERENCES}

1. Ciucă FI, Marasescu PC, Matei M, Florescu AM, Margaritescu C, Petrescu SM, Dumitrescu CI. Epidemiological and Histopathological Aspects of Tongue Squamous Cell Carcinomas-Retrospective Study. Current health sciences journal. 2018 Jul;44(3):211.

2. Perry BJ, Zammit AP, Lewandowski AW, Bashford JJ, Dragovic AS, Perry EJ, Hayatbakhsh $\mathrm{R}$, Perry CF. Sites of origin of oral cavity cancer in nonsmokers vs smokers: possible evidence of dental trauma carcinogenesis and its importance compared with human papillomavirus. JAMA Otolaryngology-Head \& Neck Surgery. 2015 Jan 1;141(1):5-11.

3. Behnoud F, Torabian S, Zargaran M. Relationship between oral poor hygiene and broken teeth with oral tongue squamous cell carcinoma. Acta Medica Iranica. 2011;49(3):159-62.

4. Singhvi H, Malik A, Chaturvedi P. The role of chronic mucosal trauma in oral cancer: A review of literature. Indian $\mathrm{J}$ Med Paediatr Oncol. 2017;38(1):44

5. Granados F, Santos-Ruiz L, Contreras M, Mellado J, Martin G, Bermudo L, Ruiz F, Aguilar Y, Yáñez I. Squamous cell carcinoma related with dental implants. A clinical cases report. Journal of Clinical and Experimental Dentistry. 2020 Jan;12(1):e98.

6. Feller L, Lemmer J. Oral Squamous Cell Carcinoma: Epidemiology, Clinical Presentation and Treatment. J Cancer Ther. 2012;03(04):263-8. 
7. Rakotoarison RA, Ralaiarimanana LF, Alson SR, Razafindrabe JB, Rakotovao FJ. Carcinome épidermoïde de la langue mobile et irritation d'origine prothético-dentaire: à propos d'une observation. Médecine Buccale Chir Buccale. 2010;16(1):53-6.

8. Fan H, Yoon KY, Kim SM, Myoung H, Lee JH, Kim MJ. Relationship between squamous cell carcinoma of the tongue and the position of dental prosthesis. J Adv Prosthodont. 2015;7(2):129.

9. Orbak R, Bayraktar C, Kavrut F, Gündogdu C. Poor oral hygiene and dental trauma as the precipitating factors of squamous cell carcinoma. Oral Oncol Extra. 2005 Jul;41(6):109-13.

10. Piemonte E, Lazos J, Belardinelli P, Secchi D, Brunotto M, Lanfranchi-Tizeira H. Oral cancer associated with chronic mechanical irritation of the oral mucosa. Med Oral Patol Oral Cirugia Bucal. 2018.

11. Manoharan S, Nagaraja V, Eslick GD. Ill-fitting dentures and oral cancer: A meta-analysis. Oral Oncol. 2014 Nov;50(11):1058-61.
12. Rotundo LD, Toporcov TN, Biazevic GH, Carvalho MB, Kowalski LP, Antunes JL. Are recurrent denture-related sores associated with the risk of oral cancer? A case control study. Revista Brasileira de Epidemiologia. 2013;16:705-15.

13. Velly AM, Franco EL, Schlecht N, Pintos J, Kowalski LP, Oliveira BV, Curado MP. Relationship between dental factors and risk of upper aerodigestive tract cancer. Oral oncology. 1998 Jul 1;34(4):284-91.

14. Lockhart PB, Norris CM, Pulliam C. Dental factors in the genesis of squamous cell carcinoma of the oral cavity. Oral Oncol. 1998 Mar;34(2):133-9.

15. Ren J, Qi M, Yuan Y, Tao X. Radiomics of apparent diffusion coefficient maps to predict histologic grade in squamous cell carcinoma of the oral tongue and floor of mouth: a preliminary study. Acta Radiol. 2020 Jun 14;028418512093168. 